E. C.S., aet. 55.-Complained of failure of sight in right eye. R.V. $6 / 24 \overline{\mathrm{c}} \frac{-1 \text { D.sph. }}{-1 \text { D.cyl. hor. }}=6 / 18$ not improved. L.V. 6/12 $\overline{\mathrm{c}}$ $\frac{-0.5 \text { D. sph. }}{-0.75 \text { D. cyl. hor. }}=6 / 6$ (R.V.in 1918 had 6/5 $\bar{c}-1$ D. sph.) Sight in right eye failed gradually. Cyst in right upper lid. Incised. Noticed the improvement in his vision the day following the incision of the cyst.

18 January, 1921.-R.V. $6 / 9 \mathrm{c} \frac{-0.5 \mathrm{D} . \mathrm{sph} .}{+1 \mathrm{D} . \mathrm{cyl} \text {. down }}$ and in $60^{\circ}=6 / 5$ slowly.

L.V. $\frac{\overrightarrow{\mathrm{c}}-0.5 \mathrm{D} . \mathrm{sph} .}{0.75 \mathrm{D} \text { cyl }}=6 / 5$ most. J $1 \mathrm{c}+2.5$

D.sph.added.

These three cases appear to me to be of some interest, and, as far as I know (although probably the condition has been noticed before) I do not think it has been recorded, and the first case certainly found me unprepared for the dénouement.

All these cases had a Meibomian cyst in the upper lid, which showed some degree of chronicity, and the cysts were hard and protuberant. All three patients had become accustomed to the cyst and did not associate their failure of vision with its presence. All complained of a gradual failure of sight in the eye having the cyst, and all recovered normal vision after removal of the tumour. I should say that the ocular tension in all three cases was rather subnormal than normal, although I have no accurate tonometric measurements.

The amount of temporary astigmatism produced varied with the size of the tumour, the first case having by far the largest cyst. The second case seems to have increased the hypermetropia as well as the astigmatism. The retinoscopic shadows were broken up and whorled as in conical corneae in all three cases.

I have to thank Mr. McGillivray for his note regarding the first patient and Mr. Leslie Paton, who saw her after I did.

\title{
SOME EXAMPLES OF IDIOSYNCRASY
}

BY

\section{T.' HARRISON BUTLER \\ BIRMINGHAM}

THE effects of an idiosyncrasy may occasionally cause serious symptoms and may affect the reputation of the practitioner who is responsible for administering the remedy which has had an unusual effect. It seems wise, therefore, that cases of this type should be 
recorded. I have collected the following examples which are of an unusual type, but which might easily occur to any ophthalmic surgeon.

\section{Linseed.}

Nurse B. consulted me about her swollen eyes. She told me that whenever she makes a linseed poultice, or handles the seed in any form, she gets an acute conjunctivitis, which begins in from one to two hours after contact. This has happened four or five times, and the resulting inflammation has lasted some days and been cured with difficulty. Invariably the right eye has suffered most severely.

The night before I saw Nurse B. she made a linseed poultice with the usual result.

The conditions found were the following: Right Eye. There is great chemosis of the lower ocular and palpebral conjunctiva, and in the lower cul-de-sac there are flakes of fibrinous matter. The upper lid looks slimy when everted. The eye is but slightly injected. Left eye. The appearance is similar, but the inflammation and swelling are very much less.

A simple boric lotion was ordered, and later a 5 per cent. solution of protargol. The eye took over a week to return to its normal appearance. The matron of the Leamington Hospital tells me that she recollects a nurse who developed urticaria whenever she handled linseed.

\section{Yellow Oxide of Mercury.}

Mrs. H., aged 50, came to the Warneford Hospital, and was found to be suffering from chronic conjunctivitis and blepharitis. I ordered her a quarter per cent. solution of sulphate of zinc with yellow oxide of mercury ointment.

In a week she returned with severe eczema of the lids. She said that each time she used the ointment the skin of the lids became inflamed. I told her to give up the yellow oxide ointment and continue with the zirrc lotion; the eyes rapidly got well. I have no recollection of any other case in which this stock remedy caused any irritation of skin.

\section{Holocain.}

I had occasion one afternoon to use a drop of 1 per cent. solution of holocain for two elderly ladies, with a view to taking the tension with the Schiötz tonometer. I used the same solution for each. In the one case no pain was complained of and there were no aftereffects. The other lady said the drops caused intense pain. The same evening the family doctor asked me to see my patient at her hoùse. She was in bed and obviously ill, she had been vomiting, and had had some diarrhoea. Both eyes were much inflamed, and there was a mucoid discharge. Several days elapsed before the lids became normal. I think that there is little doubt that the lady had 
a peculiar idiosyncrasy, and that holocain was highly toxic to her. ' Needless to say, she was very angry with me. The solution was not a fresh one, and contained a little chloretone to prevent the growth of moulds.

\section{Chloretone.}

This substance is largely used for the purpose indicated. Recently several of my patients have complained of pain after the instillation of cocain and homatropin. I tried the cocain upon one of my boys, and he too complained bitterly. The cocain solution was furnished by Parke Davis, and I have had it by me for some time. I am inclined to ascribe the pain to the chloretone, or to some decomposition product of chloretone. I have now had my solutions made up without this drug, and I have had no complaints of pain. I have used the Parke Davis solution for years, and so I wonder whether any change takes place after some time which produces an irritating substance.

\section{Cocain Eserin Sequence.}

Because of the trouble mentioned with the holocain solution I threw it away, and then found that for some time I could not get any more. This led to another instance of idiosyncrasy.

Mr. W., aged 70, is under my care with chronic glaucoma. Although his tension is raised, there are at present no symptoms; and, as he has a fistula in his back following nephrotomy, I am postponing operation as long as possible. He sees me from time to time, and I take his tension with the tonometer. He was one of those who complained of my holocain, and when I was without this drug I used a drop of cocain. This dilated the pupil, so before I dismissed him I instilled a drop of eserin. He told me that after he left my house he felt very giddy and faint and had difficulty in getting home. I did not ascribe this to the drops used because I knew that he was a nervous highly-strung man. Next time he came I used the same drops and with a worse result. No ill-effects followed the use of cocain or eserin alone. It is quite common for young persons with strongly-developed accommodative power to feel very giddy when eserin is used after homatropin, and for this reason I never use eserin; but in the middle-aged and aged, with feeble or no accommodation, one does not expect it. When I was unable to get holocain I used the cocain eserin sequence scores of times for tonometry, and I have had no other example of this nature. I can only imagine that $\mathrm{Mr}$. W. has an idiosyncrasy for this sequence. The cases I have cited show that we must always be on the look out for these peculiarities, and that when our patients tell us that they react abnormally to certain drugs, we must act upon their infomation, however unusual it may appear. 